\title{
The impact of parental income and education on the schooling of their children
}

\author{
Arnaud Chevalier ${ }^{1}$, Colm Harmon ${ }^{2}$, Vincent O' Sullivan ${ }^{3^{*}}$ and lan Walker ${ }^{4}$
}

\author{
* Correspondence: viosulli@tcd.ie \\ ${ }^{3}$ TILDA, Trinity College Dublin and \\ ESRI, Dublin \\ Full list of author information is \\ available at the end of the article
}

\begin{abstract}
We investigate the relationship between early school-leaving and parental education and paternal income using UK Labour Force Survey data. OLS estimation reveals modest effects of income, stronger effects of maternal education relative to paternal, and stronger effects on sons than daughters. Using IV to simultaneously model the endogeneity of parental education and income, the maternal education effect disappears, while paternal education remains significant but only for daughters. In our favourite specification, which proxy for permanent income, paternal income becomes insignificant. Thus policies alleviating income constraints to alter schooling decisions may not be as effective as policies which increase permanent income. JEL codes: 120; J62

Keywords: Early school leaving; Intergenerational transmission
\end{abstract}

\section{Introduction}

A considerable literature has focused on the effects of parental background on outcomes for their children such as cognitive skills, education, health and subsequent income (for a review, see Black and Devereux (2011)). Parents may affect the behavior and decisions taken by their children through genetic transmission, preferences, or/ and environment - put simply, more educated and richer parents can provide a "better" environment for their children, which creates an inequity which is the focus of sizable policy attention (see for example McLachlan et al. (2013)).

The nature of the policy interventions to address this inequity depends critically on the nature of the intergenerational transmission mechanism, and the extent to which the relationship is causal. In particular, it has proven difficult to determine whether the transmission mechanism works through inherited genetic factors or environmental factors and, to the extent that it is the latter, what is the relative importance of parental education and income? Moreover, the link between the schooling of parents and their children could be due to unobserved inherited characteristics rather than a causal effect of parental education or income per se in household production. This issue is explored in detail in the review by Björklund and Salvanes (2011).

An example of the importance of maternal education on child's outcome is provided in Currie and Moretti (2003), who found a positive relationship between maternal education and their child's birth weight, which is a strong predictor of child health. The existence of such effects provides an important argument for subsidizing education, especially in households with low income and/or low educated parents. Indeed there

C 2013 Chevalier et al.; licensee Springer. This is an Open Access article distributed under the terms of the Creative Commons Attribution License (http://creativecommons.org/licenses/by/2.0), which permits unrestricted use, distribution, and reproduction in any medium, provided the original work is properly cited. 
may be multiplier effects since policy interventions that increase educational attainment for one generation may create spillovers to subsequent generations. The literature is not entirely consistent but it is generally believed that, while raising the education of mothers and fathers has broadly similar effects on household income, the external effects on children associated with parental education are larger for maternal education than for paternal, because mothers tend to be the main provider of care within the household.

Understanding the mechanisms by which parental education may affect children's outcomes is more difficult than establishing that there is an effect. Firstly, parental education may be a direct input into the production function that generates the quality of the endowments that children have in various domains (health, ability etc.). Secondly, it may also affect the choice of other inputs. Thirdly, it may indirectly facilitate a higher quantity and/or quality of other inputs through its effect on household income. The use of policy instruments such as income transfers to attempt to break the cycle of disadvantage presumes this latter route is important.

This paper addresses an important issue in the existing literature: the causal effect of parental education on children, allowing for the separate effects of maternal and paternal education; and for the causal effect of household income, controlling for education. To date, no study has simultaneously tried to account for the endogeneity of both parental education and parental income. The distinction between education and income is important since differences in policy approaches hang on their relative effects. Using a series of British cross-sectional datasets, we begin by confirming the usual finding, using least squares, that parental education levels and paternal income are positively associated with good child outcomes: in particular, with later school leaving ${ }^{1}$. This outcome measure is important because recent UK governments have targeted a reduction in the proportion of pupils leaving at 16, and committed to a phased increase in the minimum age at which youths can leave education and training. We go on to use instrumental variable methods to take account of the endogeneity of both parental income and education. We exploit a variety of ideas for identification that have been used in other research, including changes in the minimum school leaving age for the parents; month of birth of the parents which captures early school tracking that affected the parental cohorts; and parental union status and its interactions with occupation that affect paternal income independently from education.

\section{Previous literature}

It is widely shown that children brought up in less favorable conditions obtain less education, despite the large financial returns to schooling (Heckman and Masterov (2005). Indeed there is a large correlation between the education level of parents and their children (Björklund and Salvanes (2011). However the transmission mechanism behind such intergenerational correlations has never been made clear. Krueger (2004) reviewed various contributions supporting the view that financial constraints significantly impact on educational attainment. However, Carneiro and Heckman (2004) suggest that current parental income does not explain child educational choices, but that family fixed effects that contribute to permanent income, such as parental education levels, have a much more positive role. This is the central conclusion of Cameron and Heckman (1998), using US data, and Chevalier and Lanot (2002), using the UK National Child Development Study data. 
To date, researchers have attempted to identify the exogenous effect of either parental education or of parental income, but not both effects simultaneously. The literature on estimating the causal effect of parental education on the child's educational attainment has relied on three identification strategies: instrumental variables, adopted children, and twins.

The first identification strategy, and the one most relevant to this paper, uses instrumental variables methods based on 'natural' experiments or policy reforms that change the educational distribution of the parents without directly affecting children. Black et al. (2005) exploit Norwegian educational reforms which raised the minimum number of years of compulsory schooling over a period of time, and at differential rates between regions of the country. Their IV estimates show little evidence of causal effects except for evidence of maternal education on son's education. However, Oreopoulos et al. (2006) using the same approach, but using US Census data from 1960, 1970 and 1980, report that an increase in parental education by one year decreases the probability of a child repeating a schooling year (or grade) by between two and seven percentage points. Investigating some possible mechanisms for this education transmission, Dixon et al. (2013) confirm the causal effect of paternal education on literacy and numeracy skills from as early as age four, and estimate that by age sixteen, the children of parents affected by a British school leaving age reform, gained an additional 0.1 of a standard deviation in test scores over other children. Lundborg et al. (2011) report a positive effect on cognitive, non-cognitive skills and health for Swedish children whose parents were affected by a similar reform. Of course, the minimum school leaving age is likely to affect the bottom of the schooling distribution more than the top so there is a clear case for thinking, in a heterogeneous effects model, that such estimates provide Local Average Treatment Effect estimates that are not strictly comparable to OLS. However, to the extent that policymakers are particularly concerned about early school leavers, such estimates are still of interest.

Alternative strategies to account for the endogeneity of parental education is to account for genetic effects by comparing adopted and natural children (Sacerdote (2004) or Plug (2004)), or the children of twins (Behrman and Rosenzweig (2002). The conclusions from these identification strategies tend to support positive effects of paternal education and no effect of maternal education in twin studies, and positive effects of both parents in adoption studies. For example, Bjorklund et al. (2006) uses a register of Swedish adoptees, which allows controls for both natural and adoptive parents' education. After correcting for the potential bias caused by non-randomness in this population, they find that genetics account for about $50 \%$ of the correlation in education between generations but also that the causal effect of adoptive parents' education remains highly significant; i.e. nurture is an important factor.

Holmlund et al. (2011) investigate whether the disparities in results in the literature are due to differences in the sample used or in the identification strategies. Using Swedish Population Register data, they implement all three methods, i.e. twins, adoptees and IV. Their results are consistent with the weight of the existing literature. In twin studies, the maternal effect is small and about half of the paternal education effect. This conclusion is reversed when using adoptee samples. When relying on IV to estimate the causal effect of parental education, the paternal effect is never significant but the maternal effect is quite large. They also find that there are non-linearities in the effect of education with the effect of parental education being larger at higher levels of education. Pronzato (2012) notes that 
the estimates for maternal education are sensitive to size and selection, in a way that can reconcile the results from different studies.

The literature on the causal effects of parental earnings or incomes on educational outcomes is not as extensive as the literature on parental education. Blanden and Gregg (2004) review US and UK evidence on the effects of policy changes which largely focus on improving short-term family finances (see also Almond and Currie (2010). These include initiatives such as variation in welfare-to-work reforms which change the extent of financial support available, or the Moving to Opportunity (MTO) experiments in the US, which provided financial support for higher housing costs associated with moving to more affluent areas ${ }^{2}$. Confounding factors create sizable challenges in assessing the impact of income on child educational attainment. For example welfare reforms may create exogenous income 'shocks' but they also are aimed at increasing parental labor supply, which may also affect child educational attainment.

In the UK, the Educational Maintenance Allowances (EMA's) provided a sizeable means tested cash benefit conditional on participation in education (Dearden et al. 2009). Evaluations of the EMA policy trials showed enrollments increased by up to $6 \%$ in families eligible for full subsidies. However, this transfer was conditional on staying in school and so this reform is not directly informative about the effects of unconditional variations in income.

Other studies have relied on intertemporal variation in incomes between siblings, but it is unclear that parents do not take compensatory actions in the face of differential financial resources associated with each sibling. If they do, then sibling studies estimate the effects net of those actions. Other studies look at value added in the form of changes in outcomes associated with changes in income over time to difference out unobserved heterogeneity. Similar studies use early measures of outcomes as controls for unobserved heterogeneity. However, estimation of such lagged dependent variable models are, in general, inconsistent in the presence of fixed child or family effects. Nor are they very satisfactory ways of dealing with endogeneity because income may, itself, respond to lagged outcomes - for example, a failing child may stimulate a parent to work harder, to provide more financial resources to allow the child to improve.

In the absence of convincing experimental evidence and because of doubts over the validity of sibling-based studies, instrumental variables have been used to identify the effect of parental income effects on child outcomes. Shea (2000) uses union status (and occupation) as an instrument for parental income. The identifying assumption is that unionized fathers are not more 'able' parents than nonunionized fathers with similar observable skills. Mayer (1997) uses variation in family income caused by state welfare rules, income sources and income before and after the education period of the child, as well as changes in income inequality. While strong identification assumptions are used in both these studies, they both find that changes in parental long-run income have only modest and sometimes negligible effects on the human capital of the children ${ }^{3}$. Finally, Jenkins and Schluter (2002) is notable for being one of the few studies to control for both income, at various ages, and education. They study the type of school attended (vocational or academic), using a small German dataset, and find income late in the educational period is more important than early stage income. However, income effects are small relative to education effects. However, the analysis assumes exogenous income and parental education. 


\section{Data, sample selection and sources of exogenous variation}

Our analysis is based on the Labour Force Survey (LFS) - a quarterly survey of households in the U.K. In each quarter there are roughly 120,000-160,000 respondents (more in earlier surveys) from the approximately 50,000-65,000 households surveyed. Households are surveyed for five consecutive quarters. We pool the data from households in the fifth quarter over the period 1993-2012 ${ }^{4}$. Children aged 16 to 18 living at home are interviewed in the LFS, so parental information can be matched to the child's record only when children are living with their parents. Our sub-sample consists of those children observed in LFS at ages 16 to 18 inclusive (and therefore have made their decision with respect to post compulsory education participation) which is approximately 56,000 observations, or $4 \%$ of all LFS respondents. This corresponds closely to the population of 16 to 18 year olds in census data.

The age range we consider is limited because we need to observe respondents while they are still living at home in order to observe parental background (respondents are not asked directly about their parents). An examination of British Household Panel Survey data suggests that only $6 \%$ of children aged $16-18$ have already left home. However, this censoring in the LFS data becomes more severe with older teenagers - whilst 98\% of 16-year-old children are observed living with both parents, this proportion falls to $88 \%$ for those aged 18 years old ${ }^{5}$. We therefore drop 2,581 teenagers who do not live with their parents and a further 12,995 who live with only one of their parents, since we need to observe both paternal and maternal education.

Due to these age restrictions, the key outcome of interest in this paper is the decision to participate in post-compulsory schooling, defined as a dummy equal to one if the 16 to 18 year old child is either in post compulsory education at present or was in education between 16 and 18 but had left school by the time of interview ${ }^{6}$. Only 16 year olds who are surveyed between September and December are included to ensure information on their post- compulsory education decision is available. To arrive at our final sample we also drop observations from Scotland and Northern Ireland. Although these regions changed their minimum school leaving ages at different times than England and Wales, they also have quite distinct education systems. This drops another 5,342 observations.

Moreover, for our instruments to be observable in the data we impose the following additional restrictions: we select teenagers whose father is working and reporting his income; both parents were born after 1933 (and so were not affected by the earlier raising of the school leaving age from 14 to 15 , and whose school leaving is unlikely to have been directly affected by World War II); both parents were born in the United Kingdom and are currently resident in England or Wales ${ }^{7}$. We also drop observations with missing data on the variables of interest. The details of the original LFS data and the impact of the selection criteria on the variables of interest can be seen in Table 1. Focusing on children living with both parents means that our sample is disproportionally composed of children staying in. While the final set of restrictions severely cut the sample size $(16,798$ observations left), this does not alter the mean age and educational attainment of those 16-18 year-olds living with both parents. As such, our final sample appears representative of the population of 16-18 year old living with both parents.

Figures 1 and 2 show the participation rate in post-compulsory schooling in our final sample broken down by paternal and maternal education. The education of the 
Table 1 Sample selection from pooled LFS 1992-2012

\begin{tabular}{lccccc}
\hline & $\begin{array}{c}\text { All those } \\
\text { aged 16, 17 or 18 }\end{array}$ & $\begin{array}{c}\text { Living away } \\
\text { from parents }\end{array}$ & $\begin{array}{c}\text { Living with } \\
\text { one parent }\end{array}$ & $\begin{array}{c}\text { Living with } \\
\text { both parents }\end{array}$ & $\begin{array}{c}\text { Final } \\
\text { sample }\end{array}$ \\
\hline Age distribution: & & & & & \\
\% aged 16 & 23.08 & 10.34 & 24.26 & 23.5 & 24.01 \\
\% aged 17 & 39.84 & 29.87 & 41.12 & 40.06 & 39.92 \\
\% aged 18 & 37.09 & 59.78 & 34.62 & 36.44 & 36.07 \\
\% staying on at 16 & 75.08 & 50.02 & 72.37 & 77.46 & 78.12 \\
\hline Observations: & 56,650 & 2,581 & 12,995 & 41,074 & 16,798 \\
\hline
\end{tabular}

Note: The following are dropped from the penultimate column to form the final sample in the following sequence: families residing in heavily oversampled Northern Ireland (1,893 observations), families residing in Scotland $(3,449)$, families where the parents were not born in England and Wales but who arrived after finishing their schooling (6,372), very old or very young parents (317), those missing basic demographic information such as date of birth (280), where father is not working $(4,004)$ or self employed $(4,353)$ or unknown $(328)$, union status of father unknown $(1,316)$ or has no or missing reported earnings $(1,964)$.

children appears closely correlated with the education of their parents, particularly up to a school leaving age of 18 . Having parents with more education than this level does not substantially affect the staying-on probability of children, which is then almost $100 \%{ }^{8}$. The fraction of sons with post compulsory schooling is 30 points higher for father with a degree (leaving age of 21) compared to those who left school at 15 . There are some sizable gaps between the participation of girls and boys from lower educated parents. Among this group sons are more than 10 percentage points less likely to participate than daughters However, these gender gaps in educational attainment narrow with parental education. Despite the restriction to construct it, the sample displays the expected relationship of interest.

Table 2 shows some selected statistics for the sample used in our analysis. The postcompulsory schooling participation rate is $74 \%$ for boys and $83 \%$ for girls ${ }^{9}$. There are large, statistically significant, differences in the parental education and household income levels between those that remain in school compared to those that leave: almost one year extra of parental education on average and more than 20\% higher paternal earnings. Additionally, early leavers typically have parents who are two years younger.

Parental income is potentially endogenous either because it is correlated with unobservable characteristics which are correlated with the child's educational attainment, or because the parental education effect is transmitted through income. Following Shea (2000), we assume that union membership status creates an exogenous change in income, which is independent of parenting ability and the child's educational choice.

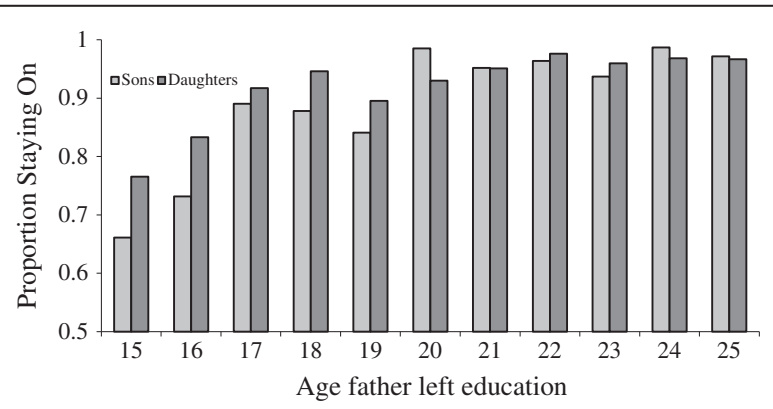

Figure 1 Post compulsory participation by paternal education. 


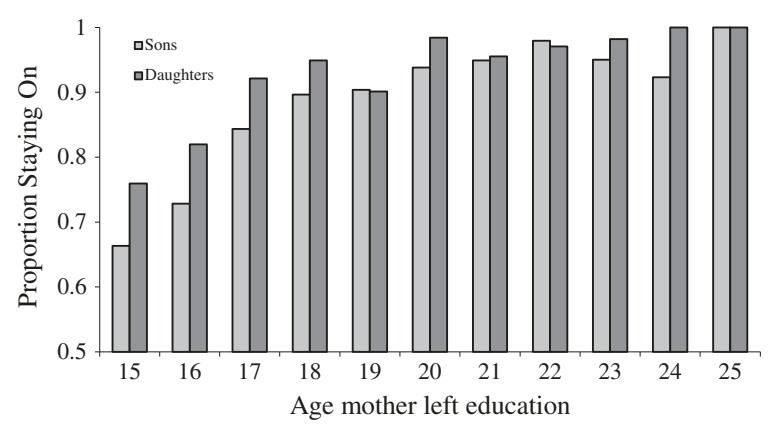

Figure 2 Post compulsory participation by maternal education.

Indeed the raw data, presented in Table 2, shows that children who stayed on were just as likely to have unionized fathers as children who do not stay on in education.

Lewis (1986) and much subsequent work, demonstrates that wages vary substantially with union status, even after controlling for observable skills. This is also the case in our data. Figure 3 shows the kernel densities of the earnings of union member fathers and non-union fathers. The raw union/non-union earnings gap for fathers in our selected sample is $8 \%$. If union wage premia reflect rents rather than unobserved ability differences it seems plausible to make the (stronger) identifying assumption, used in this paper; that union status, controlling for occupation, is uncorrelated directly with the parental influence on educational outcomes of the children ${ }^{10}$. In any event, we are assuming, as in Shea (2000), that unionized fathers (and their spouses) are not more 'productive' as parents than non-union fathers with similar observable skills. This is supported by evidence from the British Cohort Study (BCS) where we find little to suggest that parenting behavior differs across the union status of fathers ${ }^{11}$.

Parental education is likely to be endogenous. Here we rely on two sources of exogenous variation. First, we identify the effect of parental education on children's education using the exogenous variation in schooling caused by the raising of the minimum school leaving age (abbreviated as RoSLA: Raising of the School Leaving Age). Specifically, individuals born before September 1957 could leave school at 15, while those born after this date had to stay for an extra year of schooling. This policy change creates a discontinuity in the years of education attained by the parents. Figures 4 and 5 illustrate this by showing mean years of schooling by birth cohort (in 4 month intervals) around the reform date. That is, we take a narrow window of birth cohorts around the reform (+/- four years) to minimize the influence of any long-term trends across birth cohorts. There is a marked jump for parents born after September 1957 that coincides with the introduction of the new higher school leaving age. Note that, pre-reform between $30 \%$ and $40 \%$ of the parents used in this paper left school at the minimum age. So the reform did bite, and changed the behavior of a substantial fraction of individuals in the affected cohorts. Individuals affected by the new school leaving age had, on average, completed half a year more schooling than those born just before the reform. Chevalier et al. (2004) showed that the effect of this reform was almost entirely confined to the probability of leaving at 15 relative to 16 - there was little effect on educational attainment higher up the years of education 
Table 2 Descriptive statistics LFS 1992-2012 estimation sample

\begin{tabular}{|c|c|c|c|c|c|c|c|c|c|c|c|}
\hline & $\begin{array}{l}\text { Paternal log } \\
\text { earnings }\end{array}$ & $\begin{array}{c}\text { Paternal } \\
\text { school } \\
\text { leaving age }\end{array}$ & $\begin{array}{l}\text { Maternal } \\
\text { school } \\
\text { leaving age }\end{array}$ & $\begin{array}{l}\text { Paternal } \\
\text { age }\end{array}$ & $\begin{array}{l}\text { Maternal } \\
\text { age }\end{array}$ & $\begin{array}{c}\text { Father } \\
\text { affected } \\
\text { by RoSLA }\end{array}$ & $\begin{array}{c}\text { Mother } \\
\text { affected } \\
\text { by RoSLA }\end{array}$ & $\begin{array}{l}\text { Father born } \\
\text { Sept - Dec. }\end{array}$ & $\begin{array}{l}\text { Mother born } \\
\text { Sept - Dec. }\end{array}$ & $\begin{array}{l}\text { Paternal union } \\
\text { membership }\end{array}$ & $\begin{array}{l}\text { Age of } \\
\text { respondent }\end{array}$ \\
\hline \multicolumn{12}{|l|}{ Sons: $\mathbf{N}=8661$} \\
\hline \multirow[t]{2}{*}{ Did not stay in FT education (26\%) } & 5.91 & 15.83 & 15.86 & 45.39 & 43.20 & 0.43 & 0.32 & 0.30 & 0.34 & 0.42 & 17.13 \\
\hline & $(0.49)$ & 1.09) & $(0.98)$ & (5.80) & $(4.92)$ & $(0.49)$ & $(0.47)$ & $(0.46)$ & $(0.47)$ & $(0.49)$ & $(0.76)$ \\
\hline \multirow[t]{3}{*}{ Did stay in FT education (74\%) } & 6.18 & 16.72 & 16.79 & 47.21 & 45.09 & 0.41 & 0.31 & 0.31 & 0.32 & 0.41 & 17.12 \\
\hline & $(0.61)$ & $(1.49)$ & $(1.42)$ & (5.35) & $(4.72)$ & $(0.49)$ & $(0.46)$ & $(0.46)$ & $(0.47)$ & $(0.49)$ & $(0.76)$ \\
\hline & $* * *$ & $* * *$ & $* * *$ & $* * *$ & $* * *$ & $* * *$ & $* * *$ & & & & \\
\hline \multicolumn{12}{|l|}{ Daughters: $\mathrm{N}=\mathbf{8 1 3 7}$} \\
\hline \multirow[t]{2}{*}{ Did not stay in FT education (17\%) } & 5.91 & 15.85 & 15.94 & 45.27 & 43.12 & 0.46 & 0.33 & 0.31 & 0.33 & 0.41 & 17.14 \\
\hline & $(0.53)$ & $(1.06)$ & $(1.01)$ & (5.48) & $(4.70)$ & $(0.50)$ & $(0.47)$ & $(0.46)$ & $(0.47)$ & $(0.49)$ & $(0.75)$ \\
\hline \multirow[t]{3}{*}{ Did stay in FT education (83\%) } & 6.20 & 16.85 & 16.87 & 47.18 & 45.11 & 0.40 & 0.29 & 0.31 & 0.32 & 0.42 & 17.11 \\
\hline & $(0.61)$ & $(1.54)$ & $(1.43)$ & (5.28) & $(4.67)$ & $(0.49)$ & $(0.45)$ & $(0.46)$ & $(0.47)$ & $(0.49)$ & $(0.77)$ \\
\hline & $* * *$ & $* * *$ & $* * *$ & $* * *$ & $* * *$ & $* * *$ & $* * *$ & & & & $*$ \\
\hline
\end{tabular}

Note: Selected means, standard deviation in brackets. Significance level of differences between those who stay and those who do not stay. ${ }^{* * * a t} 1 \%$ level, **at $5 \%$ level, ${ }^{*} 10 \%$ level. 


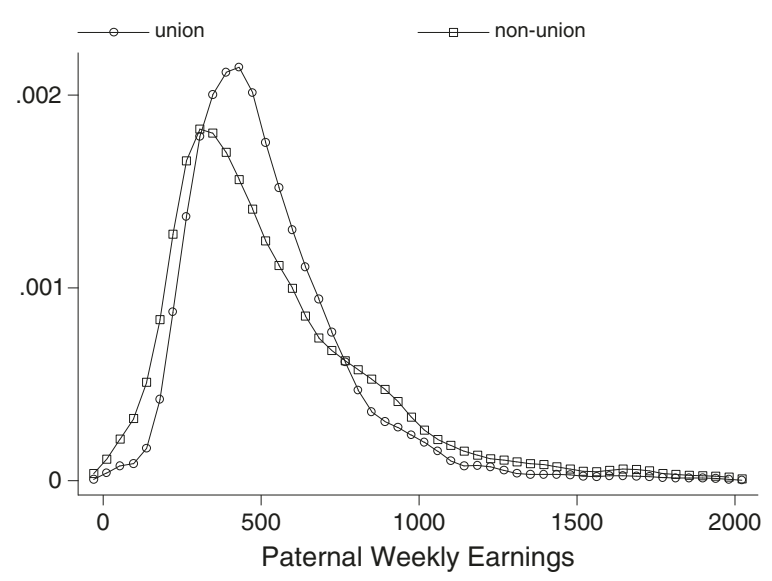

Figure 3 Distribution of Father's weekly earnings (in GBP 2005) by union status.

distribution. Hence, this reform only identifies a LATE for individuals with low levels of education. Table 2 shows that the proportion of fathers who were born before the RoSLA reform is higher than for mothers, reflecting their slightly greater age. Note also that early school leavers have younger parents who are thus more likely to have been affected by the minimum school leaving age reform.

A second source of variation in parental schooling, that we exploit, derives from parental month of birth, as in Crawford et al. (2007). There are several ways in which month of birth can affect the parents' education levels: through entry timing, leaving timing, whole group teaching, developmental differences and through peer effects. The academic year starts in September but the traditional admissions policy that reigned in the 1950's and 1960's, when most of the parents in our data were young, allowed entry at the start of the term that the child turned 5 so that there were three points of entry each year: September, January and April/May. Thus the August born would start in April/May and have two fewer terms in

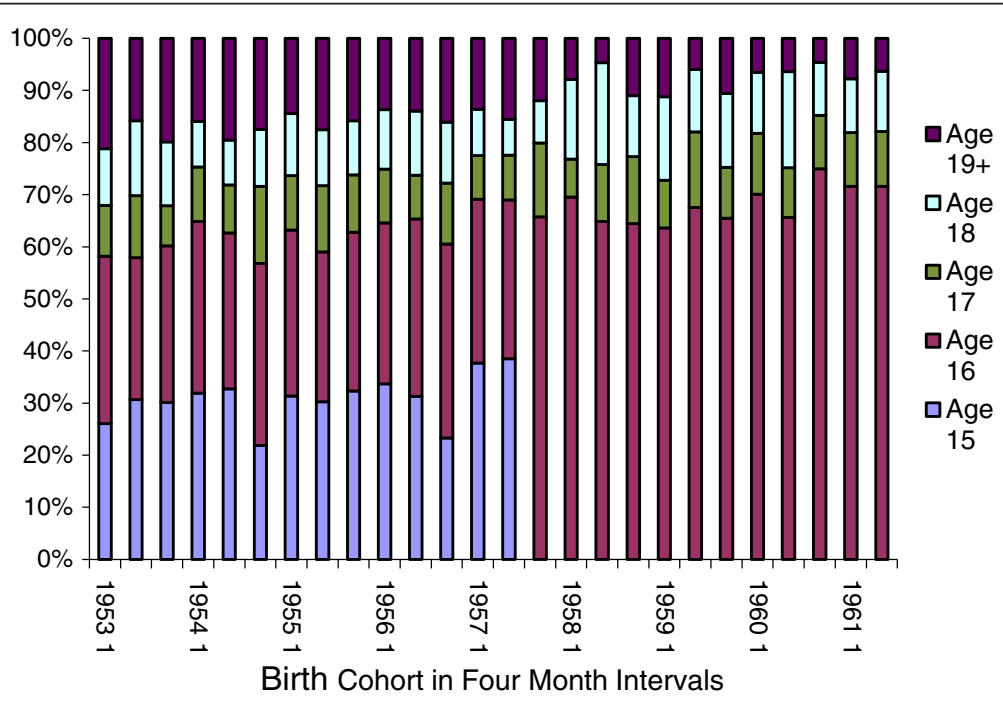

Figure 4 Distribution of paternal school leaving age by third of year of birth. 


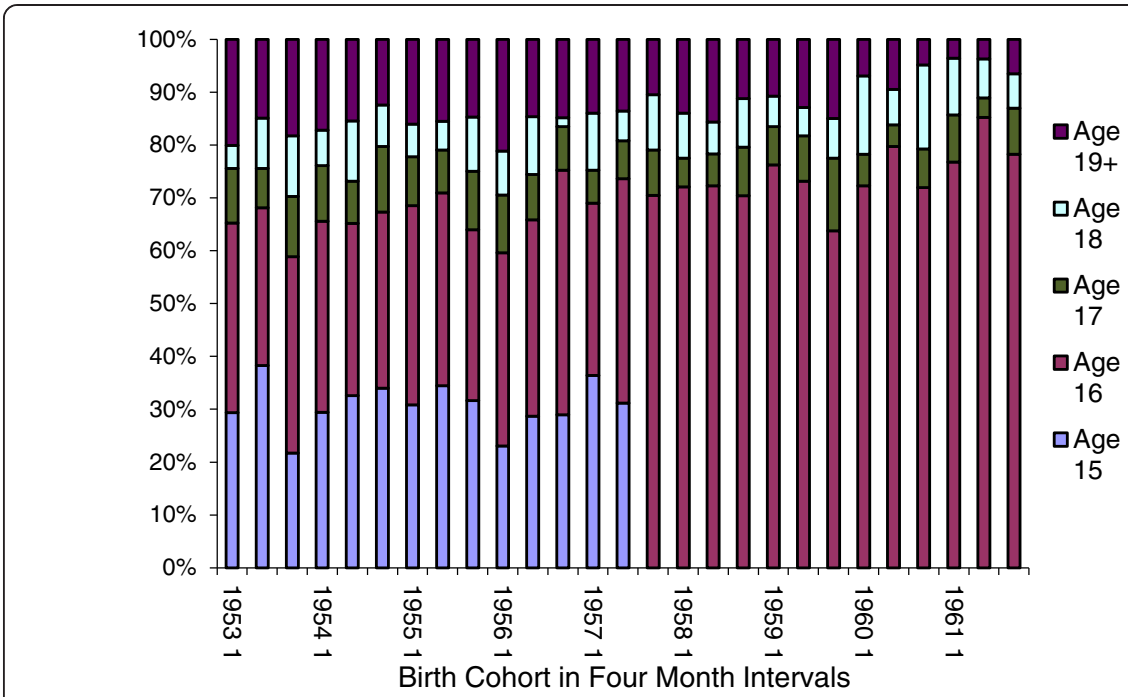

Figure 5 Distribution of maternal school leaving age by third of year of birth.

primary school than their classmates. These cohorts had two possible exit dates: children born between September and January, inclusive, could leave school at Easter, and thus not sit exams (Easter leaving rule) whether others had to stay until the end of June. In the 1950's and 60's whole class teaching was the dominant teaching method and developmental differences associated with month of birth might imply that the youngest and the oldest might fare worse than the average. Since students sit examinations at same time, they would be at different development ages when facing the same examination, penalizing younger students. Finally, peer effects might also arise because the youngest might be dominated or intimidated by the oldest.

This developmental effect is particularly important since most of the parents in these cohorts would have faced a selective schooling system where children were segregated into academic or vocational schools at the age of 11 based on a single test conducted on the same day across the whole country - known as the 11+ exam. Based on the results of this test, children were educated either in vocational or academic tracks. Children in the vocational track were much more likely to leave school at the minimum compulsory age, while those in the academic track could go on to higher secondary school and university, see Harmon and Walker (1995). These two different types of schools placed quite different expectations on the children and there was very little movement between school types after the age of 11. Figure 6 shows, by year of birth, the average age at which the parents in our data left full-time education for those who were September born, the eldest in their class cohort, compared to those who were July born, the youngest ${ }^{12}$. The youngest individuals typically obtained around $1 / 4$ of a year less education than their oldest classmates. Note that the gap closed completely for cohorts born in the early 1960's when the 11+ examination was abandoned in most areas of the country. Thus, the month of birth effect in educational achievement seems to be mostly driven by the early tracking faced by the earlier cohorts. 


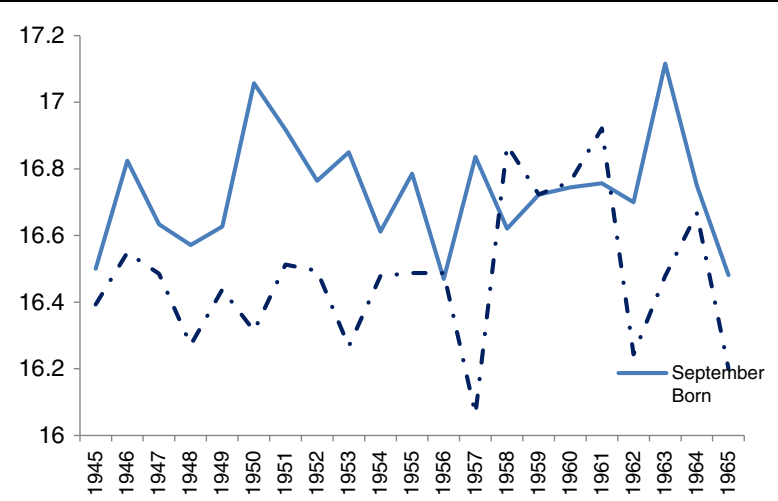

Figure 6 Average school leaving age by year of birth: England only.

\section{Estimates}

Our basic model of the impact of parental background on the post-compulsory schooling participation of their children is:

$$
P C_{\mathrm{c}}=\beta_{0}+\beta_{1} S_{m}+\beta_{2} S_{f}+\beta_{3} Y_{f}+X^{\prime}{ }_{h} \Lambda+\mathrm{f}\left(D B_{m}, D B_{f}, D B_{c}\right)+\omega_{\mathrm{c}}
$$

where the $c, m$ and $f$ subscripts refer to the child, mother's and father's characteristics within a particular household $h^{13}$. The dependent variable $P C_{c}$ is a dummy variable defining participation in post compulsory education. The effect of parental education levels, as measured in years of schooling of both the mother and father $\left(S_{w}, S_{f}\right)$, is included in the model linearly. In Figures 1 and 2 there is clearly a diminishing effect of parental education, however a linear specification more easily facilitates instrumental variable estimation in later estimates. Log parental income $Y_{f}$ is measured by father's real $\log$ gross weekly earnings from employment. $D B$ refers to date of birth (year and month) so that $f($.$) controls for cohort trends in paternal, maternal and child education.$ With respect to child's date of birth, we use a set of dummy variables for each year. With respect to parental date of birth (both year and month for both parents), we convert the date to a continuous number and then enters the model in cubic form for each parent. $X_{\boldsymbol{h}}$ contains characteristics common to all three members of the family - year of survey dummies as well as region of residence at time of survey. Equation 1 is estimated as a linear probability model to subsequently facilitate the use of instrumental variables $^{14}$.

In later extensions to our basic model, we additionally condition on paternal occupation, so that the difference in unionization between occupations does not identify the IV model. We categorize paternal occupation into blue-collar/manual versus whitecollar/non-manual. We can repeat the entire analysis using seven different occupation categories - unskilled, semi-skilled, etc. but the results are essentially the same. In other extensions to our basic model we add paternal union status, so that the identification in the IV model only comes from the interaction terms between union status and occupation. This then captures any differences in parenting behavior that unionized fathers may have.

Table 3 summarizes our OLS estimates of the effects of parental income and parental education levels on the probability of post-compulsory schooling of the child ${ }^{15}$. Specification (1) only controls for parental years of schooling. A year of maternal education is 
Table 3 OLS estimates of parental education and income on the probability of post-compulsory schooling of children

\begin{tabular}{|c|c|c|c|c|c|c|c|c|c|}
\hline Specification: & (1) & (2) & (3) & (4) & (5) & (6) & (7) & (8) & (9) \\
\hline \multicolumn{10}{|l|}{ Sons: $N=8661$} \\
\hline \multirow{2}{*}{$\begin{array}{l}\text { Maternal school } \\
\text { leaving age }\end{array}$} & $0.029^{* * *}$ & & $0.028^{* * *}$ & $0.026^{* * *}$ & & $0.026^{* * *}$ & $0.026^{* * *}$ & & $0.025^{* * *}$ \\
\hline & $(0.002)$ & & $(0.002)$ & $(0.002)$ & & $(0.002)$ & $(0.002)$ & & $(0.002)$ \\
\hline \multirow{2}{*}{$\begin{array}{l}\text { Paternal school } \\
\text { leaving age }\end{array}$} & $0.025^{* * *}$ & & $0.020^{* * *}$ & $0.017^{* * *}$ & & $0.015^{* * *}$ & $0.016^{* * *}$ & & $0.015^{* * *}$ \\
\hline & $(0.002)$ & & $(0.002)$ & $(0.002)$ & & $(0.002)$ & $(0.002)$ & & $(0.002)$ \\
\hline \multirow[t]{2}{*}{ Paternal log earnings } & & $0.118^{* * *}$ & $0.066^{* * *}$ & & $0.064^{* * *}$ & $0.040^{* * *}$ & & $0.062^{* * *}$ & $0.038^{* * *}$ \\
\hline & & $(0.008)$ & $(0.008)$ & & $(0.008)$ & $(0.008)$ & & $(0.008)$ & $(0.009)$ \\
\hline \multicolumn{10}{|l|}{ Daughters: N = 8137} \\
\hline \multirow{2}{*}{$\begin{array}{l}\text { Maternal school } \\
\text { leaving age }\end{array}$} & $0.024^{* * *}$ & & $0.023^{* * *}$ & $0.021^{* * *}$ & & $0.020^{* * *}$ & $0.021^{* * *}$ & & $0.020^{* * *}$ \\
\hline & $(0.002)$ & & $(0.002)$ & $(0.002)$ & & $(0.002)$ & $(0.002)$ & & $(0.002)$ \\
\hline \multirow{2}{*}{$\begin{array}{l}\text { Paternal school } \\
\text { leaving age }\end{array}$} & $0.015^{* * *}$ & & $0.012^{* * *}$ & $0.009^{* * *}$ & & $0.007^{* * *}$ & $0.009^{* * *}$ & & $0.007^{* * *}$ \\
\hline & $(0.002)$ & & $(0.002)$ & $(0.002)$ & & $(0.002)$ & $(0.002)$ & & $(0.002)$ \\
\hline \multirow[t]{2}{*}{ Paternal log earnings } & & $0.088^{* * *}$ & $0.050^{* * *}$ & & $0.045^{* * *}$ & $0.027^{* * *}$ & & $0.044^{* * *}$ & $0.027^{* * *}$ \\
\hline & & $(0.007)$ & $(0.008)$ & & $(0.008)$ & $(0.008)$ & & $(0.008)$ & $(0.008)$ \\
\hline $\begin{array}{l}\text { Control for paternal } \\
\text { union member }\end{array}$ & no & no & no & no & no & no & yes & yes & yes \\
\hline $\begin{array}{l}\text { Control for paternal } \\
\text { blue collar occ }\end{array}$ & no & no & no & yes & yes & yes & yes & yes & yes \\
\hline
\end{tabular}

associated with a 2.9 percentage points increase in the probability of post-16 participation for boys and 2.4 percentage points for girls. The impact of paternal education is somewhat lower especially for daughters. Specification (2) examines the impact of paternal income but excludes the parental education controls and suggests an income elasticity with respect to post compulsory schooling participation of $11.8 \%$ boys and for $8.8 \%$ for girls. Finally specification (3) includes both education and income controls. The direct effects of maternal education estimated in Specification (1) are reduced very slightly. The effect of paternal education is reduced by $20 \%$ and the income effects are reduced by $40 \%$ compared to (1) and (2) respectively, highlighting the correlation between paternal education and income.

The second set of estimates (4, 5 and 6$)$ in Table 3 adds the paternal occupation status (blue collar dummy variable). This is potentially an endogenous variable, but since the unionization rate differs by occupation, when not controlling for occupation the union instrument might partially capture occupational income, which would invalidate its use. Since paternal occupation is correlated both with paternal education and (permanent) income, the estimates for these parameters are reduced. In specifications (5) and (6) income is best interpreted as deviation within blue/white collar status. As such, the income effects are reduced by about $30 \%$ for boys and about $50 \%$ for girls. Note, however, that when controlling for occupation, adding paternal income only marginally reduces the effect of paternal education on the educational attainment of children. Thus indicating that the correlation between paternal education and income mostly captures the permanent component of income, rather than income shocks.

The third panel of Table 3 shows the effects of parental education and paternal earnings when controlling for the effects (not interacted) of paternal union 
membership and paternal blue-collar dummy (specifications (7), (8) and (9)). The effects of parental education are virtually unchanged compared to the estimates presented in columns (4) to (6); supporting the view that paternal union membership has no direct effect on the education decision of his children. For girls, the effect of paternal income also remains unchanged compared to specifications (5) and (6) while for boys it decreases marginally.

To summarize these results: one additional year of maternal education is associated with an increase in the probability of staying on of around 2-2.5 percentage points for maternal education (larger effects on boys) and a smaller effect of paternal education between 1 and 2.5 percentage points, especially for girls. The gap between the effect of maternal and paternal education increases when measures of, or proxies for, income are introduced since paternal education is correlated with paternal income. Note also that the current income effects are greatly reduced when a proxy for permanent income (the father occupation variable) is controlled for. The income effects are in the same range as those obtained by Dearden et al. (2009) in their evaluation of the Education Maintenance Allowance. However, the EMA was a (conditional) cash transfer of only £30 per week, so the estimated income elasticities reported here appear quite small. The effects of parental education are in the higher range of those reported by Oreopoulos et al. (2006) for drop-out in the US.

To simultaneously control for the potential endogeneity of paternal income and parental schooling, we specify the following system of first stage equations for maternal education, paternal education and the log of paternal earnings:

$$
\begin{aligned}
& S_{m}=\mathrm{g}\left(D B_{m}, D B_{f}, D B_{c}\right)+\mathbf{X}_{\mathbf{h}}^{\prime} \Gamma+\mathbf{Z}_{\mathbf{f}, \mathbf{m}}^{\prime} \Lambda+\psi_{\mathrm{m}} \\
& S_{f}=\mathrm{h}\left(D B_{m}, D B_{f}, D B_{c}\right)+\mathbf{X}_{\mathbf{h}}^{\prime} \boldsymbol{\Pi}+\mathbf{Z}_{\mathbf{f}, \mathbf{m}}^{\prime} \mathrm{H}+\chi_{\mathbf{f}} \\
& Y_{f}=\mathrm{k}\left(D B_{m}, D B_{f}, D B_{c}\right)+\mathbf{X}_{\mathbf{h}}^{\prime} \Xi+\mathbf{Z}_{\mathbf{f}, \mathbf{m}}^{\prime} \Theta+\phi_{\mathrm{f}}
\end{aligned}
$$

The functions $\mathrm{g}(),. \mathrm{h}(),. \mathrm{k}($.$) are polynomials of order three in parental dates of birth$ and include a set of dummy variables in child year of birth. $\mathbf{X}$ contains the control variables. As in the OLS estimates, we consider two specifications: controlling for occupation and controlling for occupation and union status. $\mathbf{Z}$ contains the instrumental variables. $\psi_{\mathrm{m}}, \chi_{\mathrm{f}}, \phi_{\mathrm{f}}$ are idiosyncratic errors terms. The instruments are as discussed above: a dummy variable RoSLA, which takes the value one for parents born after September 1957, a linear function in month of birth ${ }^{16}$, which takes the value of one for September born through to twelve for August born, and either the interaction of paternal union membership (PUM) and paternal blue collar status (i.e. manual worker) or this interaction and the direct effect of paternal union status. Given that we control for smooth trends in parental date of birth, the RoSLA variable acts as a regression discontinuity and picks up the effects of the reform alone.

We estimated a wide variety of first stages and corresponding second stage equations to examine the sensitivity of the second stage estimates to the set of exclusion restrictions used to define the instrumental variables. Our IV estimates have the property, which is also a feature of the OLS estimates, that the addition of income to a model containing just parental education levels makes little difference to the parental education estimates. Thus, we refrain from presenting specifications that contain just parental income or just parental education levels and Table 4 only reports our favorite specification. 
Table 4 Instrumental variable estimates: first stage regressions

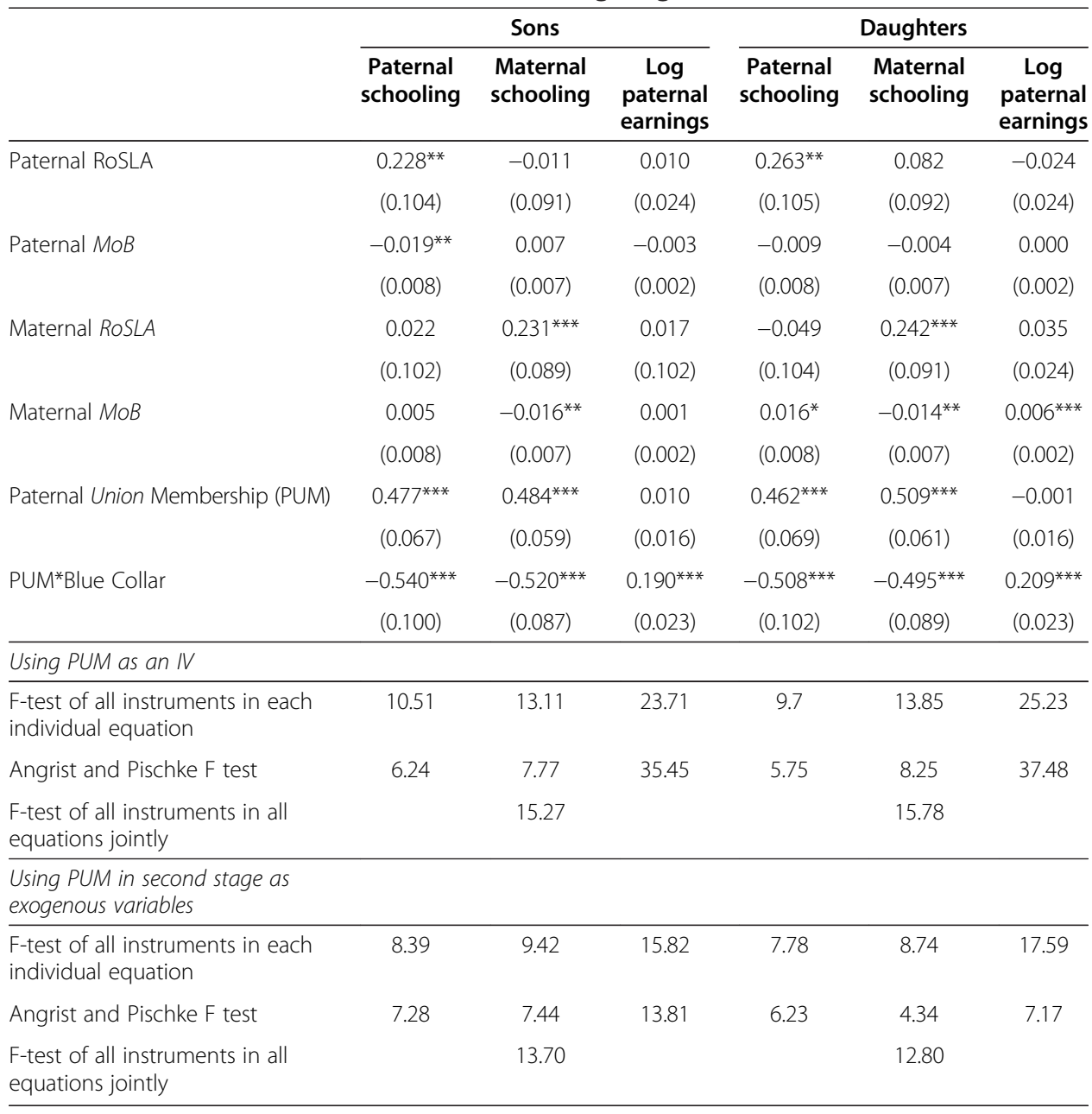

All instruments appear in all first stage equations. All second stage exogenous controls appear in all first stage equations but estimates for these are omitted from these tables in the interest of brevity.

${ }^{*} p<.1{ }^{* *} p<.05 .{ }^{* * *} p<.01$.

All of the instruments are used in each of the first stage equations. There are some cases where an instrument is having a significant effect in an equation that a priori it would not be expected to have an effect on. For example, paternal union membership has a significant effect in the maternal schooling equation. This is probably a byproduct of correlation between our instruments caused by assortative mating.

The instruments for education have almost identical effects on father's and mother's education. Being affected by the raising of the school leaving age increased the affected parent's education by 0.23 of a year, while an August born child, on average, left school one fifth of a year earlier than a September born child. Note that, instrumenting education by only one of the instruments at the time makes little difference to the size and significance of the estimates (not reported) suggesting that the two instruments identify the effects of exogenous shocks to parental education through different mechanisms. So while both instruments identify a population of marginal students, these are not identical populations.

For paternal earnings we consider two specifications either union membership is included as an instrument as well as its interactions with blue collar status or it is 
included in the second stage and only the interaction is used as an instrument (blue collar status is always included in the second stage). These two specifications of the model result in identical first stages. Only the interaction of union membership and occupation is significant in the earning equation showing that blue-collar workers drive the union premium. Union membership has no effect on white collars earnings but increase blue-collar earnings by up to $20 \%$.

Weak instruments can result in biased estimates in the second stage equation so it is important that the instruments' relevance is tested. Since we have three endogenous variables there are various ways for testing the weakness of the instruments. We thus present different F-tests to test the joint significance of the instruments. First, we test for the joint significance of all the instruments in all the equations separately. For sons, the F-statistic for the joint significance of all the instruments in the Paternal Schooling Equation is 10.51. The F-statistic for maternal schooling and paternal earnings are 13.11 and 23.71 respectively. Additionally, we present an F-test of the joint significance of the instruments in the three equations simultaneously, which for the sons' equation is 15.27. These statistics compare reasonably favorably with the Stock and Yogo (2002) suggested cut-off of around 10. Additionally, we present the modified F-statistic of Angrist and Pischke (2009) which is suggested for cases of multiple endogenous variables, and which partials out the effects of the instruments on the other endogenous variables. These F-tests range from 6.24 to 35.45 for sons. There are no suggested critical values of this test but using the Stock and Yogo's rule of thumb would suggest that the instruments for education are somehow weak. We repeat the exercise for our favored specification, i.e. treating union membership as a control variable. We reach similar conclusions regarding the validity of the instruments under this more strict exclusion restriction. These conclusions are similar for the estimates based on daughters.

Table 5 shows the second stage estimates and reports the probability of staying on separately for sons and daughters, and for the two specifications, i.e. excluding union status or not. The effect of maternal education is considerably reduced and always imprecisely estimated. The estimate itself varies widely from specification to specification. The effect of paternal education on sons is never significant and varies widely, but for daughters the IV point estimate, at 0.07 , is ten times the size of the OLS estimate. The lack of significance of parental education is similar to the findings of Black et al. (2005) for Norway. However, we find a reasonably strong effect of paternal education on daughter's education, as in twin studies, which is much larger than the OLS estimate. The IV estimates should be interpreted as LATE. The fathers affected by the school reform had large financial returns to that decision (Harmon and Walker 1995) which may have changed how they value education. It remains unclear why this affects daughters' behavior more than boys.

The effect of paternal earnings varies with the set of instruments used. There is never a statistically significant effect of paternal earnings on girls and the coefficients vary widely depending on the specification. The estimated effect of paternal earnings on sons also varies between specifications. It is large and significant when earnings are instrumented by both union status and its interaction with blue collar status. However when only the interaction of union and occupation is used as instruments and both union and occupations are controlled for in the second stage (columns 2 of Table 5), the estimates become very imprecise and unstable. Again, those results are similar to 
Table 5 Instrumental variable estimates: LFS 1992-2012

\begin{tabular}{lcccc}
\hline Specification: & $\mathbf{( 1 )}$ & $\mathbf{( 2 )}$ & $\mathbf{( 3 )}$ & $\mathbf{( 4 )}$ \\
\hline Population & ALL & ALL & Blue & White \\
\hline Sons: & & & & \\
Maternal school leaving age & 0.011 & -0.030 & 0.016 & -0.016 \\
& $(0.037)$ & $(0.045)$ & $(0.082)$ & $(0.044)$ \\
Paternal school leaving age & 0.028 & 0.003 & -0.051 & $0.077^{*}$ \\
& $(0.036)$ & $(0.040)$ & $(0.082)$ & $(0.044)$ \\
Paternal log earnings & $0.157^{* *}$ & -0.025 & $0.192^{* *}$ & -0.221 \\
& $(0.066)$ & $(0.126)$ & $(0.082)$ & $(0.234)$ \\
\hline N & 8661 & 8661 & 3,833 & 4,828 \\
\hline Daughters: & & & & \\
Maternal school leaving age & 0.001 & 0.021 & -0.009 & 0.017 \\
Paternal school leaving age & $(0.034)$ & $(0.055)$ & $(0.060)$ & $(0.036)$ \\
& $0.070^{* *}$ & $0.078^{*}$ & 0.015 & 0.055 \\
Paternal log earnings & $(0.035)$ & $(0.041)$ & $(0.077)$ & $(0.038)$ \\
& -0.031 & 0.039 & -0.030 & 0.059 \\
\hline$N$ & $(0.060)$ & $(0.165)$ & $(0.074)$ & $(0.188)$ \\
\hline Instruments & 8137 & 8137 & 3,630 & 4,507 \\
\hline Second stage controls & RoSLA & RoSLA & RoSLA & RoSLA \\
& MoB & MoB & MoB & MoB \\
& PUM & & & PUM \\
& PUM*Blue & PUM*Blue & & \\
\hline
\end{tabular}

Notes: Standard errors in parentheses. Specifications include year of survey dummies, regional dummies, dummies of child's year of birth, cubics in parental dates of birth. RoSLA is a dummy for the Raising of School Leaving Age, MoB stands for Month of Birth (linear), PUM for Paternal Union Status, and Blue indicates if the father workers in a manual job. ${ }^{*} p<.1 .{ }^{* *} p<.05$.

those obtained by Shea (2000) and suggest that (unconditional) cash transfer might not alter the transmission of education choice from one generation to the next.

We now discuss some robustness checks of our results. In the last two columns of Table 5, we present estimates for two sub-populations: blue and white collars, since the first stage results presented in Table 4, suggest that our instrument for parental earnings has power only for the blue-collar population ${ }^{17}$. The paternal union status dummy variable, which captures unionized white-collar fathers, has no effect on paternal earnings whereas the interaction of paternal union status and paternal blue-collar status has a positive (coefficient of around 0.2 depending on gender of the child) and statistically significant effect. Looking at the second stages for these sub-groups, we again find no effect of parental characteristics on the outcomes of daughters. For sons, we see that there are heterogeneous effects of paternal earnings - there is a significant effect of blue-collar fathers' earnings on sons but no effect of white collar fathers' earnings on sons. This suggests that there is heterogeneity in the effect of parental income on participation, with poorer sons likely to benefit from financial transfers. For white-collar fathers, there is a weak effect of paternal education on sons.

We now investigate the validity of our estimates when using the Raising of the School Leaving Age as an IV for parental school leaving age. There may be concerns that including date of birth of parents (converted to a continuous variable) as a cubic 
Table 6 Effect of "fake" and actual raising of school leaving Age on parental education

\begin{tabular}{|c|c|c|c|c|}
\hline \multirow[b]{2}{*}{ Year of "Fake" reform } & \multicolumn{2}{|c|}{ Sons } & \multicolumn{2}{|c|}{ Daughters } \\
\hline & $\begin{array}{l}\text { Effect of father's } \\
\text { RoSLA dummy } \\
\text { variable on age } \\
\text { father left } \\
\text { education }\end{array}$ & $\begin{array}{l}\text { Effect of mother's } \\
\text { RoSLA dummy } \\
\text { variable on age } \\
\text { mother left } \\
\text { education }\end{array}$ & $\begin{array}{l}\text { Effect of father's } \\
\text { RoSLA dummy } \\
\text { variable on age } \\
\text { father left } \\
\text { education }\end{array}$ & $\begin{array}{c}\text { Effect of mother's } \\
\text { RoSLA dummy } \\
\text { variable on age } \\
\text { mother left } \\
\text { education }\end{array}$ \\
\hline \multirow[t]{2}{*}{1953} & -0.078 & $-0.162^{*}$ & -0.036 & -0.132 \\
\hline & $(0.100)$ & $(0.090)$ & $(0.104)$ & $(0.093)$ \\
\hline \multirow[t]{2}{*}{1954} & 0.007 & $-0.232^{* *}$ & -0.100 & $-0.169^{*}$ \\
\hline & $(0.101)$ & $(0.090)$ & $(0.104)$ & $(0.093)$ \\
\hline \multirow[t]{2}{*}{1955} & $0.214^{* *}$ & -0.046 & -0.064 & 0.031 \\
\hline & $(0.101)$ & $(0.090)$ & $(0.104)$ & $(0.093)$ \\
\hline \multirow[t]{2}{*}{1956} & $0.193^{*}$ & 0.090 & 0.021 & 0.134 \\
\hline & $(0.102)$ & $(0.090)$ & $(0.104)$ & $(0.092)$ \\
\hline \multirow[t]{2}{*}{1957 True reform } & $0.241^{* *}$ & $0.247^{* * *}$ & $0.276^{* * *}$ & $0.258 * * *$ \\
\hline & $(0.104)$ & $(0.089)$ & $(0.104)$ & $(0.091)$ \\
\hline
\end{tabular}

Estimates used in this table based on first stage equations that control for year of survey dummies, regional dummies, dummies of child's year of birth, cubics in parental dates of birth, paternal union status, paternal blue collar status and interaction of union status and blue collar worker.

${ }^{*} \mathrm{p}<.1 .{ }^{* *} \mathrm{p}<.05 .{ }^{* * *} \mathrm{p}<.01$.

polynomial and using a dummy variable for being affected by RoSLA (being born after September 1957) is not correctly modeling the discontinuity in educational attainment and only picks up a general upward trend in parental educational attainment. In Table 6, we show our estimates of the effect of "fake" RoSLA reforms on parental education. We simulate the effects of miscoding RoSLA to dates prior to its actual introduction. For example, in the first row of Table 6, we see that when RoSLA is set to have happened in 1953, there was no significant effect of the RoSLA dummy variable on father's education and a negative effect (albeit only significant at the 10\% level) on maternal education. Comparing the effects of the fake reforms with the actual reform (the bottom row of Table 6) we see that the actual reform is picking up the discontinuity in attainment rather than just upward trends because the dummy variables are positive and highly statistically significant for both fathers and mothers for both the sample of sons and the sample of daughters, which is never the case in any of the fake reform cases.

Another concern about our results may be that the general lack of significance of the IV results is driven by a high correlation between the instruments, which would make the model under-identified. Indeed, the correlations between the parent's ROSLA status is high (0.67) but the correlation between parental month of birth is close to zero. To investigate this issue further, we simplified our model and estimated the effect of paternal income and maternal education, or paternal income and paternal education, only. Using only one parent at the time also means that the estimate will capture the education effect of the other parent. Since parents are positively matched, we would expect the estimates obtained with a single parent to be larger than those obtained when including both parent's education. The point estimates obtained are almost identical to those reported for the full model but surprisingly are less precisely estimated ${ }^{18}$. As such it seems unlikely that our results are driven by the correlation between the instruments.

One final concern is that the various criteria introduced to select our sample, i.e. living at home with both parents with father's income being correctly reported, 
resulted in an unrepresentative sample. To address this, we re-estimated our OLS results on a sample of two-parent households that included Northern Ireland and Scotland residents, non-English born parents, or very old/young parents. This produces a very similar set of results as in Table 3, although the maternal education effect is much smaller. Running the model on a sample of single mothers raises questions of female labour supply that are beyond the scope of this paper to correct, but the crude regressions show that both maternal education and maternal earnings have positive and significant effects on the child remaining in full-time education ${ }^{19}$. As such we are confident that our conclusions are not driven by sample selection.

\section{Conclusion}

This paper has addressed the intergenerational transmission of education and investigated the extent to which early school leaving (at age 16) may be due to variations in permanent income and parental education levels. Least squares revealed conventional results - stronger effects of maternal than paternal education and stronger effects on sons than daughters. We also found that the education effects remained significant even when household income was included. Current income remains significant even when some measures of permanent income are included which indicates that some children could be financially constrained in their decision to attend post-compulsory education.

When using paternal union status and the interaction of paternal union status and paternal occupation as instrumental variables, the IV results strengthen the role of paternal education, but for daughters - one year of paternal education increases the probability of his daughter staying on by seven percentage points. In contrast, maternal education has no statistically significant impact on the probability of remaining in education for either sons or daughters - a result which is robust to the range of instrument sets used. In treating paternal income as endogenous, the elasticity of income on schooling decisions increases by a multiple of four for sons, but there is no effect on daughters. The results with respect to income are more sensitive to the instrument set used, and are less robust than the results relating to parental education.

The results reinforce the challenges faced by policymakers in shaping policy options to encourage greater educational participation. Policymakers often view the problem of low participation as an issue of credit constraints at the minimum school leaving age acting as a barrier to further participation. For the United Kingdom, evaluations of the pilot implementation of a means tested conditional cash transfer (Educational Maintenance Allowances (EMAs)) paid to the student show relatively large changes in participation in postcompulsory education in the 'treated' group, particularly for those with the lowest prior achievement ((Dearden et al. (2009)). This may indicate credit constraint issues, but also is consistent with a price effect from the lowering of the 'opportunity cost' of staying on. In this latter case, we cannot be sure about the extent to which this extra education is valuable to these participants. A conditional cash transfer policy may therefore carry sizable deadweight potential despite the success of the evaluations of initiatives like EMA. Indeed, recent UK evidence (Chowdry et al. (2010)) that linked administrative data for a cohort from age 11 to age 19 finds that poor attainment in secondary school is more important in explaining lower participation rates (in higher education) amongst students from disadvantaged backgrounds than income/credit constraints. 
In this paper we show that a policy of increasing family permanent income through increasing parental education would also have some positive effects, especially for daughters. More importantly, a focus on increasing participation can have 'multiplier' effects through the intergenerational impact - the recently proposed increase of the de facto school leaving age in the UK to 18 would also benefit future generations through direct intergenerational transmission of educational choice, especially through the father.

\section{Endnotes}

${ }^{1}$ We also investigate the relative effects of parental education levels and household income on educational achievement at age 16. High school students in England and Wales usually study up to ten subjects until the age of 16 which are then examined at the end of compulsory schooling in the school year that they reach 16. These are scored as $A^{*}$ to $G$ with $A^{*}-C$ being regarded as passing grades. The government's objective is that $60 \%$ of all 16 year olds pass in at least five subjects. This level of achievement is usually required to progress into senior high school. Not surprisingly our estimated results for the effect on junior high school achievement closely parallel the results for early school leaving and so are not reported here, but are available on request.

${ }^{2}$ MTO programs are associated with noticeable improvements in child behavior and test scores, but whether these are caused by the financial gain, changes in the physical environment, school effects and/or peer-group changes remains unclear. Work on MTO by Sanbonmatsu et al. (2011) suggests that MTO-driven neighbourhood effects on academic achievement were not significant.

${ }^{3}$ Acemoglu and Pischke (2001) use similar arguments to Mayer (1997) and exploit changes in the family income distribution between the 1970's and 1990's. They find a 10 percent increase in family income is associated with a $1.4 \%$ increase in the probability of attending a four-year college. Loken (2010) studies the long-term effect of family income on children's educational attainment using the Norwegian oil shock in the 1970 s as an instrument. They find no causal relationship.

${ }^{4}$ Prior to 1993 there was no earnings data in LFS. Between 1993 and 1998, earnings data is available only for fifth wave respondents; from 1998 the earnings data is collected in the first and in the final wave.

${ }^{5}$ Re-estimating without the 18 year olds showed no economically or statistically significant differences in results.

${ }^{6} \mathrm{We}$ may thus underestimate participation if individuals postpone attending postcompulsory education until they are over 18 . We believe this is a rather rare event.

${ }^{7}$ Whilst this may create some selection bias it would be difficult to overcome this in our data. Since parental separation is probably more likely for children with large (but unobservable) propensities to leave school early, and it is also likely to be negatively correlated with parental education and income we might expect to underestimate the effect of income and education on the dependent variables. We also examined the effects of living with a stepparent but found that while there was a negative stepparent effect, the interaction between this and education or income proved insignificant. Results are available on request.

${ }^{8}$ Note that due to institutional characteristics there are only a few parents with school leaving age of 17, 19, 20 and above 23. 
${ }^{9}$ Official statistics from the Department for Children, Schools and Families show $67 \%$ of boys and $75 \%$ of girls (averaged over the years examined in this paper) choosing to stay so our own staying-on figures from LFS are a little higher. This is likely to be a reflection of the selections that we have made.

${ }^{10}$ Support for the view that unionization picks up differences in labor market productivity is mixed. Murphy and Topel (1990) find that individuals who switch union status experience wage changes that are small relative to the corresponding cross-section wage differences, suggesting that union premia are primarily due to differences in unobserved ability. However Freeman (1994) counters this view, arguing that union switches in panel data are largely spurious so that measurement error biases the union coefficient towards zero in the panel.

${ }^{11}$ The British Cohort Study (BCS) data, of all children born in England and Wales in a particular week in 1970, records, in considerable detail, the attitudes and behaviours of fathers towards their children. This data suggests rather small differences in attitudes and behaviours across union status. For example, $23 \%$ on unionised fathers disagreed with the statement that "The needs of children are more important than one's own", compared to $18 \%$ of the non-unionised; $60 \%$ (62\%) of children with unionised (non-unionised) fathers watched TV less than 2 hours per day on a typical weekend day; $83 \%$ (88\%) of unionised (non-unionised) fathers read stories more than once per week; $57 \%$ (52\%) of unionised (nonunionised) fathers always (as opposed to often/sometimes/never) talked to his child even when busy; $79 \%$ (79\%) of unionised (non-unionised) fathers showed the child physical affection at least once per day and 36\% (37\%) praised the child at least once per day; $94 \%$ (95\%) of unionised (non-unionised) fathers has helped young children learn numbers, etc.; and 79\% (80\%) of unionised (non-unionised) fathers aspired for the child to continue in full-time education at age 16 . The children also reported behaviour that might well reflect parenting styles. For example, 56\% (54\%) of the children of unionised (non-unionised) fathers made their own bed and 49\% (52\%) cleaned their own room.

${ }^{12}$ We use July rather than August for this comparison since there is likely to be some ambiguity with August-born children to the extent that schools exercised discretion at the margin.

${ }^{13}$ Standard errors are clustered at the household level throughout the analysis. Only about $13 \%$ of the sample are siblings. The analysis is repeated separately for sons and daughters. Only about $7 \%$ of the sample are same-sex siblings and hence used to estimate the same equations.

${ }^{14}$ The marginal effects from probit estimation are very close to the linear probability model coefficient estimates and are available on request.

${ }^{15} \mathrm{We}$ control for smooth cohort trends by including a cubic function of parents months/years of birth. Full results are available on request. Similar estimates based on probit models are also available.

${ }^{16}$ Greater flexibility could be sought but at the cost, of course, of potential weakness in the instruments.

${ }^{17}$ The corresponding first stage equations, not reported here, were estimated separately for blue collar and white collar fathers.

${ }^{18}$ Results available on request.

${ }^{19}$ Results available on request. 


\section{Competing interests}

The IZA Journal of Labor Economics is committed to the IZA Guiding Principles of Research Integrity. The authors declare that they have observed these principles.

\section{Acknowledgements}

Financial support from the HM Treasury Evidence Based Policy programme, the Nuffield Foundation Small Grant Scheme and the award of a Nuffield Foundation New Career Development Fellowship to Harmon is also gratefully acknowledged. Chevalier is also a Research Fellow at the University College Dublin Geary Institute. We are grateful to Pedro Carneiro, Kevin Denny, Robert Haverman, Lisa Farrell, Robin Naylor, Bobbi Wolfe and seminar participants at ANU Canberra, CEMFI in Madrid, RAND in Santa Monica, the University of Glasgow, School of Public Health at Harvard University, the Melbourne Institute, RMIT, University of Warwick and the Tinbergen Institute for comments. We also thank the Associate Editor and Referees for suggestions that have greatly improved the manuscript. The data used in this paper was made available by the UK Data Archive at the University of Essex. We will provide every assistance to other approved researchers who wish to use this data to replicate and extend our analysis. Responsible editor: Pierre Cahuc.

\section{Author details}

${ }^{1}$ Royal Holloway, University of London, London, UK and IZA, Bonn, Germany. ${ }^{2}$ University of Sydney, Sydney Australia and IZA, Bonn, Germany. ${ }^{3}$ TILDA, Trinity College Dublin and ESRI, Dublin. ${ }^{4}$ Lancaster University Management School, Lancaster, UK and IZA, Bonn, Germany.

\section{Received: 21 September 2013 Accepted: 12 November 2013}

Published: 09 Dec 2013

\section{References}

Acemoglu D, Pischke JS (2001) Changes in the wage structure, family income, and Children's education. Eur Econ Rev 45(4-6):890-904

Almond D, Currie J (2010) Human capital development before age five. National Bureau of Economic Research, Inc, NBER Working Papers. 15827, Cambridge, Massachusetts, USA

Angrist JD, Pischke J-S (2009) Mostly Harmless Econometrics: An Empiricist's Companion. Princeton University Press, Princeton and Oxford

Behrman JR, Rosenzweig MR (2002) Does increasing women's schooling raise the schooling of the next generation? Am Econ Rev 92(1):323-334

Bjorklund A, Lindahl M, Plug E (2006) The origins of intergenerational associations: lessons from Swedish adoption data. Q J Econ 121(3):999-1028

Björklund A, Salvanes KG (2011) Chapter 3 - Education and Family Background: Mechanisms and Policies. In: Eric A, Hanushek SM, Ludger W (ed) Handbook of the Economics of Education, vol Volume 3, 2011th edition. Elsevier, pp 201-247

Black SE, Devereux PJ (2011) Chapter 16 - Recent Developments in Intergenerational Mobility. In: David C, Orley A (ed) Handbook of Labor Economics, vol Volume 4, Part B. Elsevier, pp 1487-1541

Black SE, Devereux PJ, Salvanes KG (2005) Why the apple doesn't fall far: understanding intergenerational transmission of human capital. Am Econ Rev 95(1):437-449

Blanden J, Gregg P (2004) Family income and educational attainment: a review of approaches and evidence for Britain. Oxf Rev Econ Policy 20(2):245-263

Cameron SV, Heckman JJ (1998) Life cycle schooling and dynamic selection bias: models and evidence for five cohorts of American males. J Polit Econ 106(2):262-333

Carneiro P, Heckman JJ (2004) Human Capital Policy. In: Heckman JJ, Krueger AB (ed) Inequality in America. MIT Press, Cambridge

Chevalier A, Harmon C, Walker I, Zhu Y (2004) Does education raise productivity, or just reflect it? Economic Journal 114(499):F499-F517

Chevalier A, Lanot G (2002) The relative effect of family characteristics and financial situation on educational achievement. Educ Econ 10(2):165-181

Chowdry H, Crawford C, Dearden L, Goodman A, Vignoles A (2010) Widening participation in higher education: analysis using linked administrative data. Institute for Fiscal Studies, IFS Working Papers: W10/04, London, UK

Crawford C, Dearden L, Meghir C (2007) When You Are Born Matters. The Impact of Date of Birth on Child Cognitive Outcomes In England. The Institute for Fiscal Studies, London, UK

Currie J, Moretti E (2003) Mother's Education and the intergenerational transmission of human capital: evidence from college openings. Q J Econ 118(4):1495-1532

Dearden L, Emmerson C, Frayne C, Meghir C (2009) Conditional cash transfers and school dropout rates. J Hum Resour 44(4):827-857

Dixon M, Gregg P, Robinson H (2013) Early, Late or Never? When does Parental Education Impact Child Outcome? IZA Discussion Paper, Bonn, Germany

Freeman RB (1994) H. G. Lewis and the study of union wage effects. J Labor Econ 12(1):143-149

Harmon C, Walker I (1995) Estimates of the economic return to schooling for the United Kingdom. Am Econ Rev 85(5):1278-1286

Heckman JJ, Masterov DV (2005) Skill Policies for Scotland. In: Coyle D, Alexander W, Ashcroft B (ed) New Wealth for Old Nations: Scotland's Economic Prospects. Princeton University Press, Princeton and Oxford, pp 119-165

Holmlund H, Lindahl M, Plug E (2011) The causal effect of parents' schooling on Children's schooling: a comparison of estimation methods. J Econ Lit 49(3):615-651 
Jenkins S, Schluter C (2002) The Effect of Family Income during Childhood on Later-Life Attainment: Evidence from Germany. DIW Discussion Papers, Berlin, Germany

Krueger AB (2004) Inequality, Too Much of a Good Thing. In: Heckman JJ, Krueger AB (ed) Inequality in America: What role for human capital policies? Edited with an introduction by Benjamin M. Friedman. Alvin Hansen Symposium on Public Policy series. MIT Press, Cambridge and London, pp 1-75

Lewis HG (1986) Union Relative Wage effects: A Survey. University of Chicago Press, Chicago

Loken KV (2010) Family income and children's education: using the Norwegian oil boom as a natural experiment. Labour Econ 17(1):118-129

Lundborg P, Nordin M, Olof Rooth D (2011) The Intergnerational Transmission of Human Capital: Exploring the Role of Skills and Health Using Data on Adoptees and Twins. IZA Discussion Paper, Bonn, Germany

Mayer SE (1997) What money can't buy: family income and children's life chances. Harvard University Press, Cambridge and London

McLachlan R, Gilfillan G, Gordon J (2013) Deep and Persistent Disadvantage in Australia. Australian Government Productivity Commission Staff Working Paper. Australian Government Productivity Commission, Canberra, Australia

Murphy KM, Topel RH (1990) Efficiency Wages Reconsidered: Theory and Evidence. In: Weiss Y, Fishelson G (ed) Advances in the theory and measurement of unemployment. St. Martin's Press, New York, pp 204-240

Oreopoulos P, Page M, Stevens AH (2006) The intergenerational effects of compulsory schooling. J Labor Econ 24(4):729-760

Plug E (2004) Estimating the effect of mother's schooling on Children's schooling using a sample of adoptees. Am Econ Rev 94(1):358-368

Pronzato C (2012) An examination of paternal and maternal intergenerational transmission of schooling. J Popul Econ 25(2):591-608

Sacerdote B (2004) What Happens When We Randomly Assign Children to Families? National Bureau of Economic Research, Inc. NBER Working Papers, Cambridge, Massachusetts, USA, 10894

Sanbonmatsu L, Ludwig J, Katz LF, Gennetian LA, Duncan GJ, Kessler RC, Adam E, McDade TW, Lindau ST (2011) Moving to Opportunity for Fair Housing Demonstration Program - Final Impacts Evaluation. US Department of Housing and Urban Development Office of Policy Development and Research, Washington DC, USA

Shea J (2000) Does parents' money matter? J Public Econ 77(2):155-184

Stock JH, Yogo M (2002) Testing for Weak Instruments in Linear IV Regression. National Bureau of Economic Research, Inc. NBER Technical Working Paper, Cambridge, Massachusetts, USA, p 284

10.1186/2193-8997-2-8

Cite this article as: Chevalier et al: The impact of parental income and education on the schooling of their children. IZA Journal of Labor Economics 2013, 2:8

\section{Submit your manuscript to a SpringerOpen ${ }^{\circ}$ journal and benefit from:}

- Convenient online submission

Rigorous peer review

- Immediate publication on acceptance

- Open access: articles freely available online

- High visibility within the field

Retaining the copyright to your article

Submit your next manuscript at $\boldsymbol{\sim}$ springeropen.com 